\title{
A SUPRESSÃO DO GERÚNDIO NO ATLAS LINGUÍSTICO DO MATO GROSSO DO SUL: UMA FOTOGRAFIA VARIACIONISTA ${ }^{1}$
}

\author{
Aluiza Alves de Araújo (UECE) \\ Francisco Geilson Rocha da Silva (FUNCAP/UECE) \\ Brenda Kathellen Melo de Almeida (FUNCAP/UECE)
}

Resumo: Com base nos pressupostos teóricos e metodológicos da Sociolinguística Variacionista (LABOV, 2008; WEINREICH, LABOV \& HERZOG, 2006), analisamos, neste estudo, a supressão do gerúndio nos dados do Atlas Linguístico do Mato Grosso do Sul, como ocorre nas palavras fervendo >fervenu / cantando >cantano. Esse fenômeno é bastante comum no Português brasileiro e tem sido observado por pesquisadores desde Amaral (1920). Utilizando um corpus constituído por 163 informantes, investigamos os seguintes fatores extralinguísticos: localidade, faixa etária, sexo. A variável sexo, selecionada pelo GoldVarb $X$ como sendo a única relevante para a análise estatística, mostra que os homens são os únicos aliados desta regra. É importante que, cada vez mais, possamos conhecer nossas variedades linguísticas, para que chegue à sala de aula uma compreensão mais científica e menos preconceituosa de fenômenos como o examinado aqui, contribuindo assim para um ensino de Língua Portuguesa mais inclusivo e menos propenso à estigmatização linguística.

Palavras-chave: Supressão do gerúndio; Sociolinguística variacionista; Atlas Linguístico do Mato Grosso do Sul.

Abstract: Based on the presuppositions theoretical and methodological of Sociolinguistics variationist (LABOV, 2008; WEINREICH, LABOV \& HERZOG, 2006), we analyzed in this study, the suppression of the gerund in the Linguistic Atlas of Mato Grosso do Sul, as It occurs in the words fervendo>fervenu / cantando>cantano. This phenomenon is quite common in Brazilian Portuguese and has been observed by researchers since Amaral (1920). Using a corpus constituent of 163 informants, we investigated the following extralinguistic factors: location, age and

1 Este trabalho é um dos frutos do projeto "A redução do gerúndio nos Atlas Linguísticos Estaduais do Brasil: uma fotografia sociolinguística", desenvolvido na Universidade Estadual do Ceará. 
gender. The gender variable, selected by GoldVarb X as the only relevant to statistical analysis shows that men are the only allies of this rule. It is important that, increasingly, we can meet our linguistic varieties, so you come to the classroom an understanding more scientific and less prejudiced of phenomena such as examined here, thus contributing to a more inclusive Portuguese language teaching and less prone to linguistic stigmatization.

Keywords: Suppression of the gerund; Linguistic variation; Linguistic Atlas of Mato Grosso do Sul.

\section{INTRODUÇÃO}

O modelo sociolinguístico, iniciado pelo linguista americano William Labov, assume a heterogeneidade linguística manifestada na língua falada como seu objeto de estudo e abraça o desafio de sistematizar o aparente "caos" revelado nessa heterogeneidade tão evidente em cada situação de fala cotidiana (TARALLO, 2007, p. 7).

Com base nos estudos de Labov (2008) e de Weinreich, Labov e Herzog (2006), analisamos, no Atlas Linguístico do Mato Grosso do Sul, o apagamento da oclusiva dental/d/ no morfema de gerúndio, como em fervendo ferveno, com o intuito de averiguar quais variáveis extralinguísticas (sexo, faixa etária e localidade) atuam sobre o fenômeno em tela.

O processo de assimilação /nd/>/n/, registrado por Amaral (1920), no falar caipira, também ocorre em outras línguas, como no italiano central e meridional, segundo Melo (1971). 
Beviláqua (2014, p. 37, grifo do autor) ilustra a ocorrência do fenômeno no Appendix Probi "grundio non grunnio", revelando que, no latim vulgar, já era documentado.

Os dados examinados neste trabalho foram extraídos do Atlas Linguístico do Mato Grosso do Sul (doravante ALMS), elaborado a partir de entrevistas realizadas nas 32 localidades da rede de pontos do Estado. Em cada localidade foram selecionados quatro informantes, estratificados por sexo e faixa etária.

Embora se baseie em dados não muito recentes, a realização deste estudo nos possibilita obter um melhor conhecimento do processo em análise na modalidade falada em Mato Grosso do Sul, ampliando o conhecimento que temos dessa variedade linguística. Esse texto poderá, assim, colaborar no trabalho exercido pelo professor de Língua Portuguesa, capacitando-o de modo que possa administrar o ensino da nossa língua de forma mais científica, mais responsável e cada vez menos preconceituosa.

\section{ESTUDOS VARIACIONISTAS SOBRE A REDUÇÃO DO GERÚNDIO NO PORTUGUÊS BRASILEIRO}

Não encontramos muitos trabalhos que se dedicaram a estudar a redução do gerúndio no morfema /ndo/. Sob a perspectiva variacionista, abordaremos apenas 
as investigações mais recentes sobre o fenômeno na modalidade oral e que já foram completamente concluídas. Por isso, escolhemos as pesquisas de Nascimento, Araújo e Carvalho (2013); Ferreira, Tenani e Gonçalves (2012); Martins e Bueno (2011) e Vieira (2011). A seguir, apresentaremos, brevemente, os principais resultados para cada um destes trabalhos.

Nascimento, Araújo e Carvalho (2013) estudaram a supressão de /d/ no gerúndio, com base em 24 informantes, que foram extraídos do banco de dados NORPOFOR (Norma Oral do Português Popular de Fortaleza), estratificados em dois níveis de escolaridade (de 0 a 4 anos de estudo e de 9 a 11 anos), três faixas etárias (15 a 25 anos, 26 a 49 anos e a partir dos 50 anos) e dois sexos (masculino e feminino). Foram analisadas as entrevistas do tipo Diálogo entre Informante e Documentador (DID) e encontradas 465 ocorrências de verbos no gerúndio, sendo 345 ocorrências do apagamento, o que equivale a $74,2 \%$ dos verbos analisados.

Foram selecionados, como relevantes para o apagamento, os seguintes fatores, nesta ordem: escolaridade, faixa etária, contexto fonético antecedente, gênero e contexto fonético subsequente. Antes do morfema /ndo/, as vogais /e/ e /a/ favorecem levemente o apagamento; já no contexto 
seguinte, as consoantes com características fonéticas semelhantes ou idênticas àquelas presentes no morfema / ndo/ são fortes aliadas do apagamento. Os falantes de 26 a 49 anos são os maiores favorecedores da redução, seguidos pelos indivíduos de 15 a 25 anos. Os informantes com baixa escolaridade beneficiam o apagamento, assim como as mulheres. A extensão do vocábulo não se mostrou uma variável relevante para a regra.

Ferreira, Tenani e Gonçalves (2012) estudam a redução do gerúndio sob a perspectiva acústica, perceptual e variacionista, mas trataremos aqui apenas dos resultados da análise variacionista. A amostra desta pesquisa se baseia em dados apenas da cidade de São José do Rio Preto (SP) e de outras cidades vizinhas (Bady Bassit, Cedral, Guapiçu, Ipiguá, Mirassol e Onda Verde). Os informantes, de ambos os sexos, tinham entre 7 e 15 anos, 16 a 25 anos, 26 a 35 anos, 36 a 55 anos, mais de 55 anos, pertenciam a quatro níveis de escolaridade (10 ciclo do fundamental, 2 은 ciclo do fundamental, ensino médio e superior completo) e também foram classificados por tipo de renda familiar: até 5 salários mínimos e de 6 a 10 salários mínimos. As 76 amostras de fala foram retiradas de narrativas de experiência pessoal. 
Os resultados apontaram que das 999 ocorrências, a aplicação da redução de gerúndio ocorreu em $72 \%$ dos casos. A variável mais importante para a regra foi a faixa etária, revelando que os informantes 7 a 15, de 16 a 25 e os de 26 a 35 anos favorecem o apagamento de gerúndio, ao contrário dos informantes de 36 a 55 anos e os de mais de 55 anos. Ferreira, Tenani e Gonçalves (2012, p. 179) entendem que estes números "indicam claramente que estamos diante de um processo de mudança em progresso [...]“. A segunda variável selecionada foi a escolaridade e mostra que à medida que cresce a escolaridade, diminui o apagamento do [d] em contexto de morfema de gerúndio. A variável sexo/gênero foi a menos relevante de todas e seus resultados indicam que a redução é favorecida pelo gênero masculino, mas não pelo feminino.

Martins e Bueno (2011), partindo de dados da fala de doze informantes - homens e mulheres - de Dourados e PontaPorã-MS, de faixas etárias distintas (de 20 a 50 anos e de 51 anos em diante) e com diferentes níveis de formação escolar (analfabetos e alfabetizados até o ensino fundamental), analisaram diversos fenômenos de variação, dentre eles, o uso reduzido do gerúndio. O estudo mostrou que 46,16\% das ocorrências registradas no corpus pertenciam à forma 
padrão do gerúndio e $53,84 \%$ manifestaram a forma reduzida. Verificou-se o seguinte: a) uma predominância da forma reduzida na fala das mulheres; b) os falantes mais jovens (de 20 a 50 anos) reduzem mais que os falantes mais velhos (de 51 em diante); c) os escolarizados tiveram menor índice de redução do gerúndio do que os não alfabetizados.

Vieira (2011) trata do apagamento de /d/ na fala de Taboco - Mato Grosso do Sul. Neste estudo, foram selecionados 4 informantes homens com idade entre 15 - 35 anos; 4 informantes homens com mais de 50 anos; 4 mulheres entre 15 - 35 anos; 4 mulheres com mais de 50 anos. Todos os informantes tinham até o nono ano do Ensino Fundamental. Ao todo, foram encontrados 485 dados, sendo que 386, a grande maioria, são da variante reduzida e 99 pertencem à variante padrão. Os resultados revelaram não haver qualquer relação entre a supressão de /d/ no gerúndio, nível de escolaridade e faixa etária dos falantes. No entanto, Vieira (2011) apontou haver semelhanças nos usos da variante reduzida na fala dos mais jovens e dos mais idosos e uma pequena supremacia masculina na aplicação da forma reduzida do gerúndio, comprovando a hipótese de que as mulheres são mais conservadoras no uso da língua. 
A pesquisa mostrou que a variável linguística "extensão do vocábulo" é bastante produtiva para a supressão de /d/, ou seja, "o tamanho do vocábulo é proporcional ao apagamento da oclusiva" (VIEIRA, 2011, p. 18), e também que o contexto fonético-fonológico precedente e seguinte contribuem para a ocorrência do fenômeno. Outra variável analisada, a classe morfológica, revela que o gerúndio, "pelo fato de o grupo /ndo/ ser uma desinência nestas formas [...], portanto, mais suscetível ao apagamento do que as formas que são, originalmente, presas ao verbo" (VIEIRA, 2011, p. 20), é extremamente favorecedor do apagamento da oclusiva.

A partir dos estudos elencados anteriormente, observamos haver uma considerável supremacia dos fatores extralinguísticos no favorecimento da supressão de /d/ no gerúndio, especialmente os fatores escolaridade e sexo, mesmo com o reconhecimento exarado em algumas pesquisas de que fatores linguísticos (extensão do vocábulo, contexto fonético-fonológico precedente e seguinte e classe morfológica) possam de igual modo contribuir para a manifestação do fenômeno da supressão de /d/ no gerúndio, porém numa escala mais modesta. 


\section{METODOLOGIA}

Os dados por nós apreciados nesse artigo são oriundos do Atlas Linguístico do Mato Grosso do Sul (ALMS). O ALMS foi um dos últimos atlas linguísticos brasileiros a ser publicado, fato realizado apenas em 2007. Em harmonia com Castro (2013, p. 568), entendemos ser recomendável reunirmos algumas informações sobre esse importante projeto, "considerando que esse tipo de material [...] não tem muita circulação entre nós", e também como uma forma de estímulo à consulta desse material, haja vista ter sido também um dos objetivos do ALMS fornecer uma contribuição para estudiosos, pesquisadores e professores da nossa língua, tendo em vista o ensino e a aprendizagem da Língua Portuguesa. Os atlas são, na verdade, uma excelente oportunidade de ensejar um contato real e concreto com a diversidade linguística do Brasil (OLIVEIRA, 2006). Conforme aponta Oliveira (2006), os informantes para as respectivas entrevistas foram selecionados de trinta e duas localidades da região sul-mato-grossense, especificamente quatro informantes de cada local (dois homens e duas mulheres). As regiões selecionadas estão espalhadas por cinco municípios principais: Três Lagoas, Corumbá, Aquidauana, Campo Grande e Dourados. “A escolha das localidades teve por base 
aspectos demográficos, históricos e sociais" (p. 174). Foram selecionados 128 informantes no total. Todos eles eram naturais dos municípios escolhidos ou pelo menos residentes neles desde os 8 anos de idade e possuíam, no máximo, até a 4ạ série do ensino fundamental. A idade dos entrevistados variava entre duas faixas etárias: a primeira, de 18 a 36 anos e a segunda, de 42 a 83 anos.

Nos inquéritos, foi utilizado um questionário de 557 perguntas, alternando-se entre questões voltadas para os aspectos fonético-fonológicos e questões voltadas para os aspectos semântico-lexicais. A obtenção de dados morfossintáticos ficou por conta de um levantamento feito a partir das narrativas dos informantes sobre situações marcantes na experiência de vida de cada um (OLIVEIRA, 2013).

Dentre os 128 informantes do ALMS, 119 forneceram dados para o fenômeno em exame, mais especificamente contamos com 69 homens e 50 mulheres.

Selecionamos todos os itens lexicais que continham o gerúndio nas cartas fonéticas do ALMS, tendo o cuidado de respeitar a transcrição fonética original e de guardar as características de cada informante quanto ao sexo, faixa etária e localidade de origem. 
Os itens lexicais examinados foram os seguintes: fervendo, mordendo, pingando, catando, escolhendo, ${ }^{2}$ restoiando, ${ }^{3}$ charcanocarniano, limpando, separando, capinando, abatendo, matando. Cada ocorrência foi codificada, considerando as variáveis controladas no estudo. A seguir, tecemos alguns comentários sobre cada uma destas variáveis.

a) Localidade

Monteiro (2000, p. 78) afirma, acerca da variável localidade, que "seja como for, não resta dúvida de que a linguagem reflete não apenas o local de origem do indivíduo, mas também o local onde ele mora e trabalha", indicando a força que essa variável possui na fala das pessoas. Por isso, vimos a necessidade de analisar os seguintes pontos do ALMS: Água Clara, Amambai, Aquidauana, Bandeirantes, Bataguassu, Bela Vista, Bonito, Camapuã, Campo Grande, Cassilândia, Corumbá, Coxim, Dourados, Eldorado, Fátima do Sul, Iguatemi, Inocência, Nabileque, Naviraí, Nhecolândia, Niaoque, Paiaguás, Paranaíba, Pedro Gomes, Ponta Porã, Porto Esperança, Porto Murtinho, Rio Brillhante, Rio Negro, Rochedo, Sete Quedas e Três Lagoas.

2 Restoiano é uma variante obtida para a questão do 351 do QSL do ALMS, que é acatar/escolher. 3 Charcano e carniano são variantes obtidas para a questão 429 do QSL do ALMS, que é a carpir. 
b) Faixa etária

Vieira (2011) mostrou haver semelhanças nos usos da variante apagamento na fala dos mais jovens (15 a 35 anos) e dos mais idosos (mais de 50 anos). Por isso, decidimos investigar, para o fenômeno em estudo, as duas faixas etárias do ALMS: a primeira, com pessoas de 18 a 36 anos; e a segunda, com pessoas de 42 a 83 anos de idade.

c) Sexo

No estudo de Ferreira, Tenani e Gonçalves (2012), os homens aplicam mais a supressão do gerúndio, diferentemente do que vimos em Nascimento, Araújo e Carvalho (2013). Decidimos também controlar a variável sexo (masculino e feminino), a fim de conhecermos qual o papel de homens e mulheres sobre o fenômeno estudado.

Embora o fenômeno tenha um número bastante representativo de ocorrências, encontramos poucas palavras no gerúndio, ao todo dez verbos, e vimos que os resultados das variáveis linguísticas sofreriam interferência do item lexical. Por isso, as variáveis controladas (localidade, faixa etária, sexo) por nós, neste estudo, são todas de natureza extralinguística. 
Todas as ocorrências foram codificadas e depois submetidas à análise estatística do programa computacional GoldVarb X (SANKOFF, TAGLIAMONTE, \& SMITH, 2005).

\section{RESULTADOS E ANÁLISE DOS DADOS}

Gráfico 1: frequências obtidas para as duas variantes analisadas na pesquisa

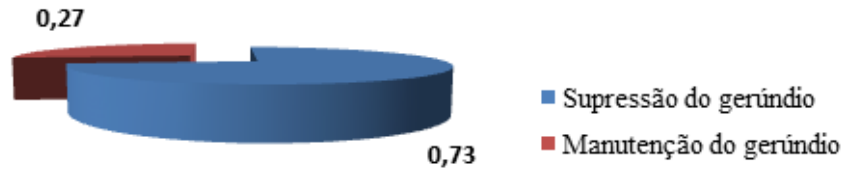

O programa GoldVarb X mostrou, na primeira análise, que houve 119 (73\%) aplicações da variante não padrão do gerúndio, isto é, com a supressão de /d/, contra 44 (27\%) realizações da forma padrão /ndo/, totalizando assim 163 ocorrências do gerúndio, o que pode ser visualizado no gráfico 1. Conforme essa primeira etapa da análise, percebemos a predominância da forma reduzida do gerúndio na fala dos informantes do ALMS.

Ainda, na etapa inicial da análise, notamos a presença de nocautes4 nas seguintes localidades: a) Amambai, com a variante ferveno (04 ocorrências) e carpino (01 ocorrência); b) Ponta Porã, com as variantes: ferveno (03 ocorrências) 
e mordeno, limpano, escolheno, matano, carniano com 01 ocorrência para cada uma das quatro últimas formas; c) Dourados, com a variante ferveno (04 ocorrências); d) Bataguassu, com a variante ferveno (04 ocorrências), escoieno (01 ocorrência) e carpinu (01 ocorrência); e) Paiaguás, com a variante ferveno (04 ocorrências).

Como tínhamos poucos dados, decidimos desconsiderar os fatores de efeito categórico, mantendo assim todas as 163 ocorrências de nosso arquivo de dados. Resolvidos todos os nocautes, realizamos uma segunda análise estatística.

Na nova análise, o GoldVarb X selecionou apenas o fator sexo como o mais relevante para a supressão de /d/ no gerúndio. As outras variáveis (faixa etária e localidade) foram descartadas pelo programa. Por isso, apresentamos, a partir de agora, somente os dados obtidos para a variável sexo.

Destacar a questão de gênero/sexo ${ }^{5}$ como influência na escolha de variantes linguísticas implica reconhecer a existência de diferenças na fala de homens e mulheres. A variável gênero/sexo, ao lado das variáveis classe social e faixa etária, apresenta-se recorrentemente em estudos de fenômenos linguísticos que contemplam a variação, isso porque, conforme Labov, "[...] as mulheres desviam

5 Apesar de no ALMS essa variável estar padronizado como "sexo", incluímos o item lexical "gênero" por ser a escolha predominante no texto das autoras. 
das formas prescritas menos do que os homens" (LABOV, 2001, p. 367 Apud SCHERRE \& YACOVENCO, 2011, p. 123), isto é, são claramente mais conservadoras. Conforme Paiva (1994, p. 37), a mulher é possuidora de maior sensibilidade ao valor social da linguagem. $\mathrm{O}$ autor ainda afirma que "se os homens tendem a favorecer a forma menos prestigiada de linguagem, as mulheres [...] têm maior sensibilidade às formas mais prestigiadas" (PAIVA, 1994, p. 72), comprovando, dessa forma, haver sim uma diferença no comportamento linguístico de ambos. Paradoxalmente, os homens parecem estar mais suscetíveis às influências dos usos de prestígio da língua, porém usam menos estas formas do que as mulheres por lhes faltar a sensibilidade para com o valor social da linguagem que sobeja entre as mulheres. Pelo menos nas sociedades ocidentais, conforme Suarez (1995, p. 99), as mulheres praticam as formas linguísticas mais aceitas, rechaçando as mais estigmatizadas "en una mayor proporción que los hombres".

Como se pode observar na tabela 1, as mulheres do ALMS, com peso relativo 0,321 , inibem a ocorrência de itens lexicais com a realização de /d/ no gerúndio, diferentemente do que ocorre com os homens que se mostram os únicos aliados do apagamento do gerúndio, comprovando, em linhas gerais, a 
hipótese de Labov (2008), segundo a qual as mulheres são mais conservadoras no uso da língua, pois tendem a escolher a variante padrão, relegando para segundo plano as formas mais inovadoras da língua, especialmente se estas forem estigmatizadas.

\begin{tabular}{|c|c|c|c|}
\hline Fatores & Aplica/Total & $\%$ & Peso Relativo \\
\hline Masculino & $69 / 79$ & 87.3 & 0.689 \\
\hline Feminino & $50 / 84$ & 59.5 & 0.321 \\
\hline
\end{tabular}

Input 0.757Significance $=0.000$

Tabela 1: atuação da variável sexo sobre o apagamento de /d/ no morfema de gerúndio

No entanto, a análise de Martins e Bueno (2011) contrariou essa hipótese ao indicar um maior uso da forma reduzida de gerúndio na fala das mulheres ( $82,5 \%$ dos casos analisados). Os homens, por outro lado, reduziram em 35,4\% dos casos, isto é, mostraram-se mais submissos à linguagem formal do que as mulheres. Esse dado se deve ao fato de que quando a mudança linguística envolve consciência social (changes from above), as mulheres utilizam mais as formas de prestígio; todavia, em "mudanças sem consciência social (changes from Bellow)", as mulheres optam mais pelas formas inovadoras (LABOV, 2001, p. 293 Apud SCHERRE \& YACOVENCO, 2011, p. 122 - 123). No entanto, o próprio Labov permanecia intrigado com essa aparente contradição. Conforme ele 
afirmou, "permanece o problema de saber por que razão as mesmas pessoas são às vezes mais 'conservadoras' e às vezes mais "progressistas'” (LABOV, 2001, p. 366 Apud SCHERRE \& YACOVENCO, 2011, p. 123).

Observando nossos dados, percebemos a predominância da forma não reduzida do gerúndio na fala de mulheres da primeira faixa etária (18 a 39 anos) em algumas cidades. Daí, vimos a necessidade de realizar um cruzamento entre a variável sexo e a faixa etária, mesmo que esta última não tenha sido selecionada pelo Goldvarb X. Este cruzamento pode ser visualizado no gráfico que se segue:

Gráfico 2: percentuais do sexo x faixa etária sobre o apagamento de /d/ no gerúndio

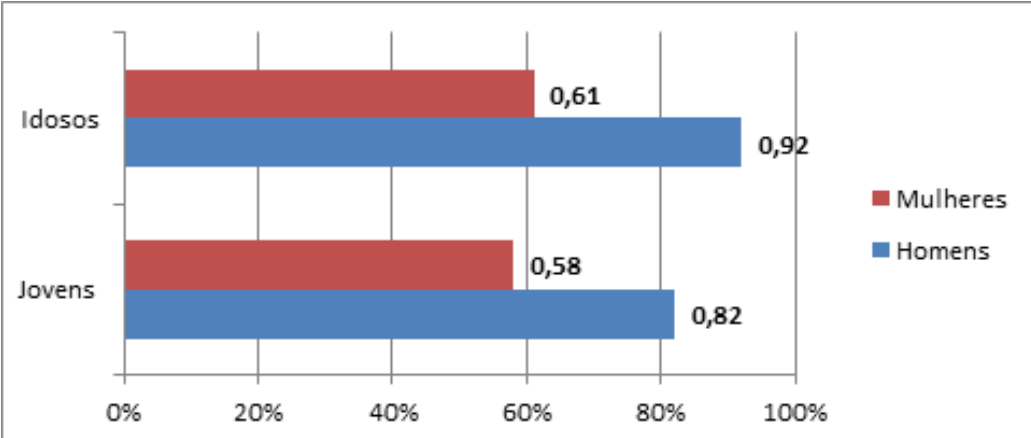

No que se refere à forma reduzida aplicada pelas mulheres, curiosamente há uma considerável predominância no uso das variantes inovadoras por parte daquelas pertencentes à segunda faixa etária (de 40 em diante). Esse fenômeno 
se observa na fala das informantes de Naviraí, Ponta Porã, Niaioque, Aquidauana, Campo Grande, Água Clara, Nabileque, Bandeirantes, Camapuã, Rio Negro, Corumbá e Cassilândia, isto é, 12 das 31 cidades analisadas. Essa hegemonia da variante inovadora no vernáculo das informantes de faixa etária mais avançada talvez se justifique pela nova postura assumida pela mulher desde o seu ingresso emancipatório no mercado de trabalho, no qual passaram a exercer funções antes realizadas apenas por homens e também a ter contato com "redes linguísticas e sociais mais diversificadas", gerando como consequência a assunção de uma postura "mais semelhante ao homem na seleção das variantes" (VIEIRA, 2011, p. 22). Mas de forma geral, como ilustra a figura 1 , houve um equilíbrio na redução do gerúndio por parte das informantes: 0,61\% para as idosas; 0,58\% para as mais jovens.

Entre os homens, percebe-se uma leve predominância da redução de /d/ no gerúndio entre os mais idosos - 0,92 contra 0,82 dos mais jovens. Talvez esse fato se deva a um processo de "ajuste dialetal" por meio do qual os homens da primeira faixa etária manifestam reconhecido aumento no uso de variantes consideradas padrão, como consequência da pressão exercida sobre os homens, pela nossa sociedade, 
para que obtenham sucesso e se responsabilizem pelo sustento financeiro da família (PAIVA, 1994).

A forte interação existente entre as variáveis "gênero/ sexo" e faixa etária é enfatizada por Kemp (1979 Apud PAIVA, 1994) num estudo em que observou vários processos de variação no francês de Montreal. Os dados elencados por essa pesquisa revelaram haver significativa semelhança no comportamento linguístico de homens e mulheres da primeira faixa etária, e consideráveis diferenças entre homens e mulheres da segunda faixa etária (PAIVA, 1994). De acordo com a figura 1, nas duas faixas etárias ocorrem dessemelhanças no comportamento linguístico de homens e mulheres, no que tange à redução de /d/ no gerúndio no ALMS. Os dados apontam um similar desequilíbrio entre os gêneros nas duas faixas etárias analisadas.

\section{CONSIDERAÇÕES FINAIS}

Nessa pesquisa, verificou-se a ocorrência da supressão de /d/ no gerúndio na fala dos informantes do ALMS. Analisando a totalidade dos itens lexicais retirados do ALMS, vimos que, em 73\% das ocorrências, houve a redução de /d/ no gerúndio. Justaposto a esse levantamento estatístico, constatamos a extrema força da variável sexo. São inúmeros os estudos sociolinguísticos que apontam a variável sexo 
como de extrema relevância para "processos variáveis de diferentes níveis (fonológico, morfossintático, semântico)" (VIEIRA, 2010, p. 2), e que apresentam regularmente as mulheres optando pelas variantes linguísticas de maior prestígio social. Nossa análise nos conduziu a algumas conclusões interessantes. Em algumas localidades, a forma canônica do gerúndio - com o /ndo/ - predominou na fala de mulheres da primeira faixa etária (18 a 39 anos). No entanto, observamos ser a variante não canônica do gerúndio mais comum entre as mulheres da segunda faixa etária (40 em diante).

Este trabalho também é uma forma de contribuir no afrouxamento do preconceito linguístico ainda tão desnecessariamente vigente em solo brasileiro. Uma das propostas apresentadas por Oliveira (2006, p. 5), como justificativa para o projeto ALMS, seria o conhecimento da modalidade falada no Mato Grosso do Sul como uma forma de contribuição "para o ensino/aprendizagem da língua portuguesa, respeitando as variações regionais". Apresentamos a supressão de /d/ no gerúndio dentro do ALMS não com finalidades normativo-prescritivistas, mas com o fito de mostrar a realidade da nossa língua. Nosso trabalho representa uma discreta colaboração 
numa mudança que necessita haver, especialmente, em sala de aula. O ensino de língua portuguesa necessita ser menos normativo, purista e alienado e mais aberto ao reconhecimento da heterogeneidade como um fator natural de toda língua; um ensino calcado nas modernas teorias linguísticas e que não hesita em se apossar dos dados oferecidos pelas pesquisas sociolinguísticas. Dessa forma, expressões como "feio", "errado" sumiriam do inventário lexical das nossas aulas de Português.

\section{REFERÊNCIAS}

Amaral, Amadeu. (1920). O dialeto caipira. São Paulo: Editora Anhembi Ltda.

Beviláqua, Kayron Campos. (2014). Appendix Probi e a variação linguística no português brasileiro (v. 2 n. 2, jan.-jun.). Curitiba: Revista Versalete. In http://www.academia.edu/10115071/appendix_prob_e_ varia\%c3\%87\%c3\%83o_lingu\%c3\%8dstica_no_portugu\%c3\%8as_ brasileiro. Acesso em junho/2015.

Castro, Vandersí de Sant'Ana. (2013). O 'r caipira' em Mato Grosso do Sul - estudo baseado em dados do ALMS, Atlas linguístico do Mato Grosso do Sul (42 (1), p. 566 - 575). São Paulo: Estudos Linguísticos. In http://www. gel.org.br/estudoslinguisticos/v42-1_sumario.php. Acesso em junho/ 2015.

Ferreira, Jesuelem Salvani; Tenani, Luciana Ester \& Gonçalves, Sebastião Carlos Leite. (2012). O morfema de gerúndio "ndo" no português brasileiro: análise fonológica e sociolinguística (v. 28, n. 1, p. 167 - 188). Uberlândia, MG: Revista Letras \& Letras. In http:www.seer.ufu.br/index. php/letraseletras/article/view/25855/14214. Acesso em maio/2015.

Guy, Gregory R. \& Zilles, Ana. (2007). Sociolinguística Quantitativa - 
instrumento de análise. São Paulo: Parábola Editorial.

Labov, William. (2008). Padrões Sociolinguísticos. (Marcos Bagno; Marta Scherre e Caroline Cardoso, Trad.) São Paulo: Parábola Editorial.

Martins, Ivone da Silva; Bueno, Elza Sabino da Silva. (2011). Estudo do gerúndio - a transformação de [nd] em [n] no Português falado na região de fronteira (v. 1, n. 4, p. 1 - 24). UEMS/Campo Grande: Sociodialeto (Online). In http:www.sociodialeto.com.br/edições/9/28092011064716. pdf. Acesso em maio/2015.

Melo, Gladstone Chaves de. (1971). A língua do Brasil (2a ed.) Rio de Janeiro: Fundação Getúlio Vargas.

Monteiro, José Lemos. (2000). Para compreender Labov. Petrópolis, Rio de Janeiro: Editora Vozes.

Nascimento, Katiene Rozy Santos do; Araújo, Aluiza Alves de \& Carvalho, Wilson Júnior de Araújo. (2013). A redução do gerúndio no falar popular de Fortaleza: um olhar variacionista (v.2, p. 398-413). Veredas, Juiz de Fora: UFJF. In http://www.uffif.br/revistaveredas/files/2014/04/21\%C2\%BAARTIGO.pdf. Acesso em junho/2015.

Oliveira, Dercir Pedro de. (2006). O Atlas Linguístico de Mato Grosso do Sul (v.9, n.2, p. 169 - 183). Signum: Estudos de Linguagem. In http://www. uel.br/revistas/uel/index.php/signum/article/view/3944. Acesso em maio/2015.

Paiva, Maria Conceição. (1994). Sexo. In: Cecília Mollica \& Maria Luiza Braga. (Orgs.). Introdução à sociolingüística: o tratamento da variação. São Paulo: Contexto.

Sankoff, David; Tagliamonte, Sali A.; Smith, Eric. (2005). Goldvarb X- A multivariate analysis application. Toronto: Department of Linguistics; Ottawa: Department of Mathematics. In http://individual.utoronto.ca/ tagliamonte/goldvarb.html. Acesso em junho/2015.

Scherre, Maria Marta Pereira \& Yacovenco, Lilian Coutinho (2011). A variação linguística e o papel dos fatores sociais: o gênero do falante em foco (n. Especial, p. 121 - 146, 1a parte). Curitiba, PR: Revista da ABRALIN, versão eletrônica: UFPR. In http://ojs.c3sl.ufpr.br/ojs/index.php/abralin/ 
article/view/32348. Acesso em junho/2015.

Suarez, Manuel V. Almeida. (1995). El factor 'sexo' em los procesos de variación y cambio (v. 33, p. 97 - 109). Espanha: Anuário de Letras: Linguística y Filologia, Universidade de La Hioja. In http://dialnet.unirioja. es/servlet/articulo?codigo=31538. Acesso em junho/ 2015.

Tarallo, Fernando. (2007). A pesquisa sociolinguística. São Paulo: Editora Ática.

Vieira, Marília Silva. (2011). Apagamento de /d/: abordagem sociolinguística sob a perspectiva do gênero sexual (v.1, n.4, p. 1 - 27). UEMS/Campo Grande: Sociodialeto (Online). In http:www.sociodialeto. com.br/edições/9/28092011063729.pdf. Acesso em maio/2015. . (2010). O gênero e os fenômenos de variação na fala (p. 1 -6). In: Seminário Internacional Fazendo gênero 9: Diásporas, Diversidades, Deslocamentos. Anais... Florianópolis: Universidade Federal de Santa Catarina. In http://www.fazendogenero.ufsc.br/9/resources/ anais/1278282124 ARQUIVO Ogeneroeosfenomenosdevariacaonafala. pdf. Acesso em junho/2015.

Weinreich, Uriel; Labov, William \& Herzog, Marvin. I. (2006). Fundamentos empíricos para uma teoria da mudança linguística. (Marcos Bagno, Trad.). São Paulo: Parábola Editorial.

Aluiza Alves de Araújo - Professora Doutora do Curso de Letras e do Programa de Pós-Graduação em Linguística Aplicada da Universidade Estadual do Ceará - UECE. Coordena o projeto A redução do gerúndio nos Atlas Linguísticos Estaduais do Brasil: uma fotografia sociolinguística, e participa do projeto Atlas Linguístico do Brasil. Contato: aluizazinha@hotmail.com.

Francisco Geilson Rocha da Silva - Bolsista de Iniciação CientíficoTecnológica ICT/ FUNCAP e graduando do Curso de Letras da Universidade Estadual do Ceará - UECE. Participa do projeto A redução do gerúndio nos Atlas Linguísticos Estaduais do Brasil: uma fotografia sociolinguística.

Contato: geilson-rocha@hotmail.com. 
Brenda Kathellen Melo de Almeida - Bolsista de Iniciação CientíficoTecnológica ICT/FUNCAP e graduanda do Curso de Letras da Universidade Estadual do Ceará - UECE. Participa do projeto A redução do gerúndio nos Atlas Linguísticos Estaduais do Brasil: uma fotografia sociolinguística.

Contato: brendakathellen@yahoo.com.br.

Recebido em 28 de junho de 2015.

Aprovado em 13 de julho de 2015. 